\title{
Teaching Reform and Exploration of the Course of Plant Nutrition Diagnosis and Fertilization in Colleges and Universities
}

\author{
Zhang Mingcong, Jin Xijun, Wang Mengxue, Zhang Yuxian, Zhan Yingce*
}

Heilongjiang Bayi Agricultural University, Daqing 163319, China

\author{
DOI: $10.36348 /$ jaep.2020.v04i04.001 $\quad$ | Received: 27.03 .2020 | Accepted: 03.04.2020 | Published: 07.04 .2020 \\ *Corresponding author: Zhan Yingce
}

\section{Abstract}

Plant Nutrition Diagnosis and Fertilization is the basic course of agricultural resources and environment major in colleges and universities, In recent years, from the aspects of optimizing the syllabus, constructing the teaching material system, designing the teaching content and reforming the teaching method, the teaching team has put forward some suggestions and implementation methods of the curriculum reform based on the needs of the development of modern agriculture in China, which aims to continuously innovate and improve the teaching quality in practice, and lays the foundation for the cultivation of innovative talents serving modern agriculture.

Keywords: Plant Nutrition Diagnosis and Fertilizations, Teaching Method, Teaching Reform.

Copyright @ 2020: This is an open-access article distributed under the terms of the Creative Commons Attribution license which permits unrestricted use, distribution, and reproduction in any medium for non-commercial use (NonCommercial, or CC-BY-NC) provided the original author and sources are credited.

\section{INTRODUCTION}

In recent years, China's higher education has developed rapidly and shown a trend of diversification, which objectively requires the classification of universities. Therefore, the concept of "researchoriented" universities and its corresponding evaluation system were introduced into the country and improved locally. The Department of Education says, "By2020, strive to form a group of research universities with national key scientific research bases, with the ability to undertake major national scientific research tasks and the basis of extensive international cooperation, make it become the center of cultivating high quality and innovative talents, the source of knowledge innovation and the important birthplace of innovation culture." Under this background, the reform of university education is booming, strengthening the construction of subject connotation, highlighting the characteristics of running a school and improving the quality of teaching, and the reform has gradually penetrated the reform and construction of curriculum. And we have carried on the exploration and the practice to the course of Plant Nutrition Diagnosis and fertilization curriculum teaching reform, and obtained a certain result.

\section{Objective Needs of Curriculum Reform of Plant Nutrition Diagnosis and fertilization}

Plant Nutrition Diagnosis and Fertilization is the basic course of agricultural resources and environment major in colleges and universities, and it is also the elective course of agriculture-related major. In recent years, with the development of the application and fertilization project in Heilongjiang CHINA, the technology of plant nutrition diagnosis has been developed rapidly. Scientific fertilization of rice, corn, soybean, wheat and other major crops using plant nutrition diagnostic techniques, this technology has not only been widely used but also has enabled farmers to obtain considerable economic benefits. With the rapid development of plant nutrition, many new methods, theories, and achievements have emerged, which makes the teaching contents of the course need to be updated. Plant Nutrition Diagnosis and Fertilization have evolved from simple technology and methodology to a more independent, systematic and comprehensive curriculum, its influence permeates many disciplines such as plant nutrition, soil, fertilization technology, pathology, plant physiology and agricultural remote sensing, it has become an essential part of the development of biology discipline. Plant Nutrition Diagnosis and Fertilization is a typical interdisciplinary and comprehensive subject, but the current teaching materials lack the latest scientific research results, development trends, and the lack of links between the various disciplines. Therefore, it is urgent to construct the teaching content system of the course Plant Nutrition Diagnosis and Fertilization and reform the teaching methods and methods. 
Problems in the Teaching of Plant Nutrition Diagnosis and Fertilization

Plant Nutrition Diagnosis and Fertilization has been a chapter in Principles and Techniques of Crop Fertilization, with the need for subject development, a separate course has only been established in recent years. After several years of accumulation, this course has formed some teaching materials, completed the production of various crop nutrition diagnosis maps, increased the intuitive teaching links and formed a combination of teaching and practice models. However, due to the short construction time, the overall and advanced nature of the curriculum needs to be gradually improved. This course mainly includes the diagnosis and treatment of deficiency symptoms in rice, corn, soybean, wheat and potato crops. The teaching method is mainly one-way teaching of "teacher teaching \&multimedia projection", this kind of teaching method cannot fully arouse the enthusiasm of students, they are in the state of passive acceptance of knowledge, the quality of teaching is not high, and the students' mastery of classroom knowledge is poor. The course examination form is single, the examination question is mostly the memory content, lacks the flexible experiment, causes the student to cram temporarily before the examination, such examination way is extremely unfavorable to the student to master this course. To this end, the contents of the course should be innovated so that the contents of the course can develop in accordance with the objective requirements of social economy, scientific and technological development and the basic direction of students' professional training.

\section{Objectives of the Curriculum Reform for Plant Nutrition Diagnosis and Fertilization}

In order to improve the teaching quality of the course of Plant Nutrition Diagnosis and Fertilization, to consolidate students' understanding and mastery of basic knowledge, and to cultivate students' ability, solving and comprehensive application of problems. After many discussions among all the teachers in the field of agricultural resources and the environment, we have reform and exploration of the teaching of this course.

\section{Coordination of Teaching Contents of Plant Nutrition Diagnosis and Fertilization and Agricultural Remote Sensing}

Remote sensing technology was originally mainly used in military, with the development of technology, it is now used in many fields of agricultural science, including field crop diagnosis and fertilization, crop yield estimation and growth monitoring, agricultural resources investigation, plant protection of certain pests and diseases investigation and monitoring. Remote sensing images can reflect the nutrient status of plants, provide the characterization of fertilization for crops, and enable crops to achieve high yield, high quality, high efficiency, and ecological security. In recent years, good results have been achieved in the diagnosis and fertilization of remote sensing images taken by satellite. Many scientific achievements have emerged, such as the research of plant nutrition diagnosis and fertilization based on remote sensing, the study of spatial variation characteristics of soil nutrients based on remote sensing, and the estimation of soil nutrients based on remote sensing. These contents enrich the content of Plant Nutrition Diagnosis and Fertilization, which can make agricultural remote sensing technology-related content, independent into a chapter of the curriculum. Such changes can increase the practicability of teaching links, broaden students' horizons, promote scientific research and innovation, and provide effective support for the sustainable development of agricultural resources and environment specialty and the expansion of plant nutrition discipline construction ideas. At the same time, it also makes a due contribution to the cultivation of remote sensing technology professionals in the Heilongjiang reclamation area.

\section{Integration of Discipline Development into Teaching Content}

The main contents of Plant Nutrition Diagnosis and Fertilization are related to the basic research methods, basic principles and basic techniques of Plant Nutrition and Principles and techniques of crop fertilization. Teachers in class, if blindly introduce concepts, theories, techniques, and methods, these abstract, difficult to understand the content is difficult to mobilize students' interest in learning. In the course of teaching, teachers can appropriately supplement some of the latest research methods and research techniques closely related to their major, which can not only enliven the classroom atmosphere, stimulate students' interest in learning, but also expose students to more new knowledge. For example, leading students into Heilongjiang reclamation area, to the field to see crop growth, on-site analysis of crop deficiency symptoms, into remote sensing ground receiving station, to understand the remote sensing image acquisition and interpretation methods, so that students feel the rapid development and change of Heilongjiang farming reclamation, have achieved better teaching results.

\section{Give Full Play to Students' Subjective Initiative and Increase the Interaction between Teachers and Students}

Plant Nutrition Diagnosis and Fertilization is a practical basic course, students can only really grasp the knowledge through practical application. For example, teachers set problems according to the curriculum syllabus; students solve problems in groups, prepare PPT, speak and teach in class with what they have learned. Students not only need to comb the content of classroom learning but also need to find relevant books and papers, such a way of learning can cultivate students' habit of positive thinking. This kind 
of teaching method needs to pay special attention to the following links: First, take the teaching material as the center, refer to the relevant reference materials, so that students can broaden their horizons in their study and deepen their understanding of the theory from many angles; Second, the teaching process of teachers should be refined, leaving more time for students to discuss in groups, students should fully respect the students' whimsical new views when reporting; The third is to assign after-class tasks, can find some controversial issues, arouse students to think, in order to improve students' creativity. The practice has proved that adopting this teaching method can effectively improve students' learning autonomy, enliven classroom atmosphere, and achieve better teaching results.

\section{Effect of Teaching Reform of the Course of Plant Nutrition Diagnosis and Fertilization}

According to the curriculum characteristics of Plant Nutrition Diagnosis and Fertilization, teachers arrange the teaching content reasonably. Combining students' reports and course experiment, combining traditional teaching methods with multimedia teaching. Fully mobilize the enthusiasm of students, active classroom atmosphere, so that the teaching effect and teaching quality has been significantly improved, but also mobilize the ability of students to use the Internet to solve problems.

Improve practical teaching links and actively contact production units and practice bases. Lead the students to walk the farm into the grassroots teach the symptoms of crop deficiency and how to fertilize on the spot, improve the students' practical ability. Students in contact with the first line of agricultural production personnel can better understand the modern cultivation system and advanced management experience, for the future into the society to lay a solid foundation.

The course Plant Nutrition Diagnosis and Fertilization involve the teaching of such courses as
Plant Nutrition, Principles and Technologies of Crop Fertilization, Agricultural Remote Sensing Technology, Botany and Soil Science. The course reform of Plant Nutrition Diagnosis and Fertilization also promotes the corresponding reform of these courses, so that the curriculum reform of agricultural-related majors can be optimized as a whole, forming a resultant force of reform and promoting the improvement of the teaching quality of the major.

\section{ACKNOWLEDGEMENTS}

This work was supported by General Research Projects on Higher Education and Teaching Reform in Heilongjiang Province (SJGY20190482), Teaching Research Project of Review and evaluation of Heilongjiang Bayi Agricultural University (NDJY1801), The Doctoral Scientific Research Start-up Foundation of the Heilongjiang Bayi Agricultural University of China (No. XYB2014-04), Youth Special Project in the 13th Five-Year Plan of Education Science in Heilongjiang Province (GJD1318025).

\section{REFERENCES}

1. Pei, S., Cui, F., \& Sun, T. (2013). The unity of scientific literacy education and humanistic spirit education in higher education. Creative Education, 3(07), 121.

2. Xin-bin WANG Ming-xia, Z. H. O. U. (2007). Reform in experimental instruction of the course of "plant nutrition and fertilizers"[J]. Journal of Southwest Agricultural University (Social Science Edition), 1.

3. Xulin, L.I.(2008). Construction and Curriculum System of Agricultural Resources and Environment Specialty [J]. Higher Agricultural Education, 10, 56-58.

4. Zhang, Y., Chen, W., Shen, Q. (2004). The Practice of Teaching Reform in the General Theory of Soil Fertilizer $[\mathrm{J}]$. Higher Agricultural Education. 11(11): 70-72. 